\section{Kidney \\ Blood Pressure Research}

\title{
Physical Performance and Clinical Outcomes in Dialysis Patients: A Secondary Analysis of the Excite Trial
}

\author{
Claudia Torino ${ }^{a}$ Fabio Manfredini ${ }^{b}$ Davide Bolignano ${ }^{a}$ Filippo Aucella ${ }^{c}$ \\ Rossella Baggetta ${ }^{a} \quad$ Antonio Barillàd Yuri Battagliad ${ }^{d}$ Silvio Bertolie \\ Graziella Bonanno ${ }^{f}$ Pietro Castellinog ${ }^{\text {Daniele Ciurlino }}{ }^{e}$ Adamasco Cupistih $^{h}$ \\ Graziella D'Arrigo Luciano De Paola Fabrizio Fabrizij Pasquale Fatuzzo ${ }^{f}$ \\ Giorgio Fuiano' Luigi Lombardi' Gaetano Lucisano' Piergiorgio Messaj \\ Renato Rapanàk Francesco Rapisarda ${ }^{f}$ Stefania Rastellig Lisa Rocca-Rey ${ }^{e}$ \\ Chiara Summarial Alessandro Zuccalàk Giovanni Tripepi ${ }^{a} \quad$ Luigi Catizone $^{d}$ \\ Carmine Zoccalia Francesca Mallamacia EXCITE Working Group
}

aCNR-IFC, Clinical Epidemiology and Physiopathology of Renal Diseases and Hypertension of Reggio Calabria, Italy; ${ }^{b}$ Department of Biomedical Sciences and Surgical Specialties -Section of Sport Sciences, University of Ferrara; 'Nephrology Unit, Ospedale Casa Sollievo della Sofferenza, San Giovanni Rotondo (Foggia); dNephrology Unit, AOU Ferrara Arcispedale S. Anna, Ferrara; eNephrology and Dialysis Unit, IRCCS Multimedica - Policlinico Multispecialistico, Sesto S. Giovanni, Milan; ${ }^{\mathrm{f} C l i n i c a l}$ Division of Chirurgical Nephrology, University of Catania - Azzurra Medical Nephrological Ambulatory and Dialysis Techniques, Catania; 'Department of Internal Medicine, University of Catania; ' ${ }^{\text {Department }}$ of Clinical and Experimental Medicine, University of Pisa; 'Nephrology and Dialysis Unit, Ospedale Pugliese-Ciaccio, Catanzaro; 'Nefrology and Dialysis Unit, IRCCS Cà Granda Ospedale Maggiore - Policlinico, Milano; kNephrology and Dialysis Unit, Ospedale Civile, Imola; 'Nephrology and Dialysis Unit, Policlinico Universitario Mater Domini, Catanzaro, Italy

\section{Key Words}

Physical performance $\bullet$ Six-minute walking test $\bullet$ Chronic kidney disease $\bullet$ Dialysis $\bullet$ Clinical outcomes

\footnotetext{
Abstract

Background/Aims: Scarce physical activity predicts shorter survival in dialysis patients. However, the relationship between physical (motor) fitness and clinical outcomes has never been tested in these patients. Methods: We tested the predictive power of an established metric of motor fitness, the Six-Minute Walking Test (6MWT), for death, cardiovascular events and hospitalization in 296 dialysis patients who took part in the trial EXCITE (ClinicalTrials.gov Identifier: NCT01255969). Results: During follow up 69 patients died, 90 had fatal and non-fatal 


\section{Kidney \\ Blood Pressure Research}

Kidney Blood Press Res 2014;39:205-211

\begin{tabular}{l|l}
\hline DOI: $10.1159 / 000355798$ & C 2014 S. Karger AG, Basel
\end{tabular}

Published onlıne: July 29, 2014

www.karger.com/kbr

Torino/Manfredini/Bolignano et al.: Physical Performance and Clinical Outcomes in Dialysis Patients: A Secondary Analysis of the Excite Trial

cardiovascular events, 159 were hospitalized and 182 patients had the composite outcome. In multivariate Cox models - including the study allocation arm and classical and non-classical risk factors - an increase of 20 walked metres during the 6MWT was associated to a $6 \%$ reduction of the risk for the composite end-point $(P=0.001)$ and a similar relationship existed between the $6 \mathrm{MWT}$, mortality $(\mathrm{P}<0.001)$ and hospitalizations $(P=0.03)$. A similar trend was observed for cardiovascular events but this relationship did not reach statistical significance $(P=0.09)$. Conclusions: Poor physical performance predicts a high risk of mortality, cardiovascular events and hospitalizations in dialysis patients. Future studies, including phase-2 EXCITE, will assess whether improving motor fitness may translate into better clinical outcomes in this high risk population.

Copyright $\odot 2014$ S. Karger AG, Basel

\section{Introduction}

Physical activity and physical performance are notoriously poor in patients with endstage kidney disease (ESKD) [1], a population with an extremely high risk of death and cardiovascular events [2]. Even though representing strictly related phenomena, physical activity and physical performance are separated entities with different metrics. Physical activity, i.e. physical engagement in daily activities, is a well-established predictor of mortality and cardiovascular events in the general population [3] and in pathological conditions such as diabetes [4] and coronary artery disease [5] and in end stage kidney disease (ESKD) as well [6-9]. To our knowledge, the relationship between actual physical performance, i.e. the objectively measured ability to perform well standardized physical efforts, and clinical outcomes in ESKD has been investigated just in a small study with a very limited number of major clinical events (just 21 deaths) [10]. The Six-Minute Walking Test (6MWT) is an established test to assess physical performance in frail elderly patients [11], and this test has been applied in clinical studies in various conditions, such as heart failure $[12,13]$ and chronic obstructive pulmonary disease (COPD) [14].

The EXCITE (EXerCise Introduction To Enhance Performance in Dialysis) study, is a large, multicentre, randomized trial whose phase - 2 (clinical outcomes and hospitalization) is still in progress. This study tests the effectiveness of an easy-to-implement program of physical training in dialysis patients. We have taken the opportunity of the EXCITE study to investigate the relationship between actual physical performance, as assessed by the SixMinutes Walking Test, on mortality, cardiovascular events and hospitalizations in dialysis patients.

\section{Patients and Methods}

The study protocol was approved by the ethical committee of our institution. All participants gave informed consent before enrolment.

\section{Patients}

The EXCITE Study is a multicentre randomized controlled trial on the effectiveness of exercise in improving physical performance and the quality of life (phase-1) and in reducing adverse clinical outcomes (mortality, cardiovascular events and hospitalizations) (phase-2) in dialysis patients. This trial is registered in ClinicalTrials.gov (Identifier: NCT01255969). In this secondary analysis, we included 296 dialysis patients who performed the 6MWT at baseline. These patients had been on regular dialysis (HD or PD) for a median time of 44 months (inter-quartile range: $26-83$ ). Haemodialysis patients ( $n=247$ ) were being treated with standard bicarbonate dialysis with non-cellulosic membrane filters of various type. PD patients $(n=49)$ were either on 4 standard exchanges day $(n=11)$ or on continuous cycling peritoneal dialysis $(n=38)$. Two hundred and six patients were treated with various anti-hypertensive drugs (76 on mono-therapy with calcium channel blockers, ACE inhibitors, sartans, alpha or beta blockers, clonidine, furosemide, 65 on double 


\section{Kidney Blood Pressure Research}

therapy, 44 on triple therapy and 21 patients on quadruple and quintuple therapy with various combinations of these drugs). The main demographic, somatometric, clinical and biochemical characteristics of the study population are detailed in Table 1.

\section{$L a b$ or a to $r y$ measurements}

Blood sampling was performed after an overnight fast. In haemodialysis patients, blood was always drawn in the morning hours (8 am - 12 am) during a mid-week day (brief dialysis interval). Serum cholesterol, albumin, calcium, phosphate, C-Reactive Protein (CRP) and haemoglobin measurements were made using standard methods in the routine clinical laboratory.

\section{Kidney Blood Press Res 2014;39:205-211}

\begin{tabular}{l|l}
\hline DOI: $10.1159 / 000355798$ & C 2014 S. Karger AG, Basel
\end{tabular}

Torino/Manfredini/Bolignano et al: Physical Performance and Clinical Outcomes in Dialysis Patients: A Secondary Analysis of the Excite Trial

Table 1. Main demographic, somatometric and clinical characteristics in the study population and correlates of Six-Minute Walking Test (6MWT).

\begin{tabular}{lcc}
\hline & $\begin{array}{c}\text { Whole group } \\
(\mathrm{n}=296)\end{array}$ & $\begin{array}{c}\text { 6MWT correlation } \\
\text { coefficient (P) }\end{array}$ \\
\hline Age (years) & $65 \pm 13$ & $\mathbf{- 0 . 5 7}(<\mathbf{0 . 0 0 1})$ \\
BMI (kg/m $\left.{ }^{2}\right)$ & $25 \pm 5$ & $-0.04(0.63)$ \\
Male sex n. (\%) & $201(68)$ & $\mathbf{0 . 2 1}(<\mathbf{0 . 0 0 1})$ \\
Current smokers n. (\%) & $48(17)$ & $-0.04(0.52)$ \\
Past smokers n. (\%) & $72(26)$ & \\
Diabetics n. (\%) & $60(21)$ & $\mathbf{- 0 . 2 0}(\mathbf{0 . 0 0 1})$ \\
On anti-hypertensive treatment n. (\%) & $206(73)$ & $0.004(0.95)$ \\
Dialysis vintage (months) & $44(26-83)$ & $-0.03(0.58)$ \\
With cardiovascular comorbidities* n. (\%) & $226(76)$ & $\mathbf{- 0 . 2 6}(<\mathbf{0 . 0 0 1})$ \\
& & \\
Systolic Blood Pressure (mmHg) & $128 \pm 20$ & $0.07(0.27)$ \\
Diastolic Blood Pressure (mmHg) & $69 \pm 11$ & $\mathbf{0 . 3 8}(<\mathbf{0 . 0 0 1})$ \\
& & \\
Cholesterol (mg/dL) & $164 \pm 38$ & $-0.08(0.23)$ \\
Hemoglobin (g/dL) & $11.0 \pm 1.9$ & $0.11(0.07)$ \\
Albumin (g/dL) & $3.9 \pm 0.4$ & $\mathbf{0 . 2 2}(\mathbf{0 . 0 0 1})$ \\
hsCRP (mg/L) & $0.7(0.4-2.6)$ & $\mathbf{- 0 . 1 6}(\mathbf{0 . 0 3})$ \\
Calcium (mg/dL) & $8.7 \pm 1.4$ & $-0.06(0.31)$ \\
Phosphate (mg/dL) & $4.9 \pm 1.5$ & $\mathbf{0 . 2 2}(<\mathbf{0 . 0 0 1 )}$ \\
& & \\
NYHA Class 0 n. (\%) & $124(44)$ & \\
NYHA Class 1 n. (\%) & $95(34)$ & $\mathbf{- 0 . 2 1}(<\mathbf{0 . 0 0 1})$ \\
NYHA Class 2 n. (\%) & $40(14)$ & \\
NYHA Class 3 n. (\%) & $20(7)$ & \\
\hline * Angina, arrhythmia, myocardial infarction, coronary surgery, angioplasty, other \\
heart surgery, claudicatio, amputations, peripheral surgery, stroke, TiA, heart \\
failure. \\
Data are expressed as mean \pm SD. median and inter-quartile range or as percent \\
frequency, as appropriate. & & \\
\hline
\end{tabular}

Six-Minute Walking Test

Physical performance was assessed at baseline with the Six-Minute Walking Test (6MWT). This test consists in a 6 minute-walk along a marked walkway on a hard, flat surface, at the maximum speed that each patient can maintain. The goal of this test is to walk as far possible in six minutes. During the walk, the patient is allowed to stop and rest whenever he/she wants, and the number of interruptions are carefully recorded by an operator. At the end of the test, the fatigue perceived by the patient is classified by the Borg Scale, a simple method that allows to rate the perceived exertion by using a scale from 0 (no exertion) to 10 (maximum exertion).

\section{Study end-points}

In this secondary analysis of EXCITE, a composite end-point including mortality, fatal and non-fatal cardiovascular events and hospitalizations was the main study end-point. Cardiovascular events were classified as follows: stroke (ischemic or haemorrhagic) documented by computed tomography, magnetic resonance imaging and / or clinical and neurological evaluation; transient ischemic attacks (TIA); myocardial infarction confirmed by serial changes of ECG and cardiac biomarkers; ECG-documented angina episodes; heart failure, diagnosed according to criteria by the AHA guideline [15]; ECG documented arrhythmia; peripheral ischemia or amputations; unexpected, sudden death highly suspected as of cardiac origin. Hospitalizations were classified in cardiovascular and non-cardiovascular using information included in the hospital records. Cause of death was assessed by 3 independent physicians. In doubtful cases, diagnosis was attributed by consensus. During the review process, involved physician used all available medical information, including hospitalization forms and medical records. In case of death occurred at home, family members and/or general practitioners were interviewed to better understand the circumstances surrounding death.

Statistical analysis

Data were expressed as mean \pm standard deviation (normally distributed data), median and inter- 


\section{Kidney \\ Blood Pressure Research}

Kidney Blood Press Res 2014;39:205-211

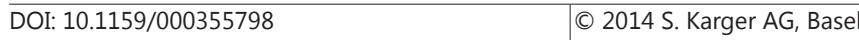

Published onlıne: July 29, 2014

www.karger.com/kbr

Torino/Manfredini/Bolignano et al.: Physical Performance and Clinical Outcomes in Dialysis Patients: A Secondary Analysis of the Excite Trial quartile range (non-normally distributed data) or as per cent frequency (categorical data). The Person correlation coefficient was used to describe correlates of 6MWT variable. The independent correlates of 6MWT were identified by correlation analysis and by multiple linear regression. Tested variables included age, gender, smoking, cardiovascular comorbidities, diabetes, antihypertensive therapy, Body Mass Index (BMI), dialysis vintage, systolic and diastolic blood pressure, cholesterol, albumin, C-reactive protein, calcium, phosphate, haemoglobin and NYHA class. All variables which correlated with 6MWT (with $\mathrm{P}<0.05$ ) were jointly introduced into the same model. Survival analyses were performed by using bivariate and multivariate Cox regression models.

In close parallelism with the strategy used for the identification of independent correlates of 6MWT (see above), in the multiple Cox Regression model we included all univariate correlates of the combined end point (with $\mathrm{P}<0.05$ ). Statistical analysis was performed by using standard statistical packages (SPSS for Windows, Version 20, Chicago, Illinois, USA; STATA for Windows, Version 13, College Station, Texas, USA).

\section{Results}

The flow-chart describing the recruitment basis of the study population and the subsequent selection process, from eligibility to randomisation, is reported in Fig. 1 and the baseline characteristics of patients randomised to the study intervention are described in Table 1. Enrolled patients had a mean age of 65 year. Sixty-eight of them were male, $17 \%$ were current smokers, $26 \%$ were past smokers. Twenty-one per cent of patients were diabetics and $76 \%$ had cardiovascular comorbidities.

\section{Correlation analyses}

Baseline 6MWT, expressed as number of meters walked in 6 minutes, significantly correlated with age $(\rho=-0.57, P<0.001)$, gender $(\rho=0.21, P=0.001)$, cardiovascular comorbidities $(\rho=-0.24, P<0.001)$, diabetes $(\rho=-0.20, P=0.001)$, diastolic blood pressure $(\rho=$ $0.38, \mathrm{P}<0.001)$ albumin $(\rho=0.22, \mathrm{P}=0.001)$, phosphate $(\rho=0.22, \mathrm{P}<0.001)$, CRP levels $(\rho=$ $-0.16, P=0.03)$ and NYHA class $(\rho=-0.21, P<0.001)$. In a multiple linear regression analysis including all univariate correlates of 6MWT, only age (beta $=-0.55)$, gender (beta $=0.16)$, and cardiovascular comorbidities (beta $=-0.17$ ) maintained an independent association with 6MWT $(\mathrm{P} \leq 0.02)$.

\section{Survival analyses}

The median follow up was 3.3 years (interquartile range: 2.7-3.5 years). During this period, 69 patients died, 90 had fatal or non-fatal cardiovascular events, 159 were hospitalized. Overall, 182 patients had the composite end-point death/cardiovascular events/hospitalizations. In a bivariate Cox regression model, including the allocation arm as covariate, an increase of 20 meters walked during the 6MWT significantly $(\mathrm{P}<0.001)$ 


\section{Kidney Blood Pressure Research}

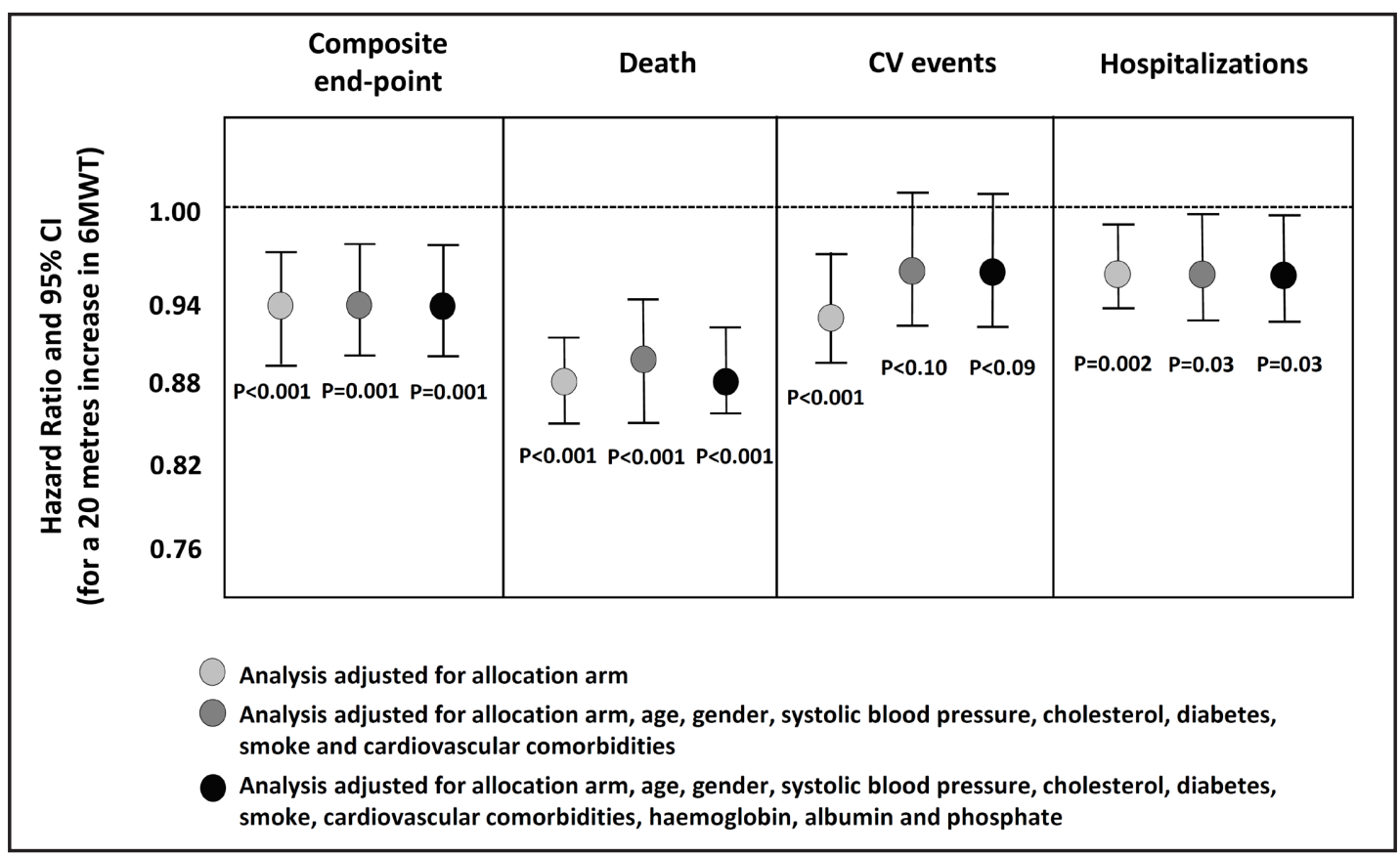

Fig. 2. Hazard ratio and $95 \% \mathrm{CI}$ associated to an increase of 20 walked metres during the six-minute walking test (6MWT) for the composite end-point (A), all-cause mortality (B), fatal and non-fatal cardiovascular (CV) events (C) and hospitalizations (D).

reduced the risk of the composite end-point by $6 \%$. Similar results were obtained in bivariate analyses of the individual end-points. In these models, an increase of 20 meters significantly reduced all-cause death by $12 \%(\mathrm{P}<0.001)$, fatal and non-fatal cardiovascular events by $7 \%(\mathrm{P}<0.001)$, and all-cause hospitalizations by $4 \%(\mathrm{P}=0.002)$. The relationship between physical performance and the combined end-point was confirmed in a model adjusting for age, gender, systolic blood pressure, cholesterol, diabetes, smoking, cardiovascular comorbidities and allocation arm (HR: 0.94, CI: 0.91-0.98, P=0.001) (Fig. 2). By the same token, physical performance by 6MWT predicted all-cause death (HR: 0.89, CI: 0.84-0.94, $\mathrm{P}<0.001$ ) and hospitalizations (HR: 0.96, CI: 0.92-0.99, $\mathrm{P}=0.03$ ). A similar trend was observed for CV events, but this relationship did not reach statistical significance (HR: 0.96, CI: 0.91$1.01, \mathrm{P}=0.10$ ). Forcing risk factors peculiar to ESKD (haemoglobin, albumin and phosphate) into the model did not modify these relationships (Fig. 2).

\section{Discussion}

This study shows that 6MWT, a test commonly used to measure exercise capacity and motor fitness, predicts the risk for mortality, cardiovascular events and hospitalizations in chronic kidney disease patients on dialysis.

Physical activity, either measured by questionnaires [16, 9] or by accelerometers [17] or pedometers [18], is about 50\% less in dialysis patients than in age and sex matched individuals. In the Dialysis Outcomes and Practice Patterns Study (DOPPS), self-reported activity was an independent predictor of death and exercising at least once a week predicted a $27 \%$ risk reduction [19]. Similar results emerged from the Wave 2 study of the United States Renal Data System (USRDS) [7] and in a study based on accelerometry [8].

While physical activity estimates engagement in daily activities, metrics of physical performance provide objective measures of motor fitness. As such, metrics of physical 


\section{Kidney \\ Blood Pressure Research}

Kidney Blood Press Res 2014;39:205-211

\begin{tabular}{l|l}
\hline DOI: $10.1159 / 000355798$ & C 2014 S. Karger AG, Basel
\end{tabular}

Published onlıne: July 29, 2014

www.karger.com/kbr

Torino/Manfredini/Bolignano et al: Physical Performance and Clinical Outcomes in Dialysis Patients: A Secondary Analysis of the Excite Trial

performance looking at walking speed like Six-Minute Walking Test (6MWT), measure cardiorespiratory endurance, muscle endurance and strength as well as balance and coordination. The 6MWT has been applied in the whole age spectrum $[19,20]$ at population level and in several conditions, including chronic congestive heart failure $[13,21]$ and other cardiac conditions [22], COPD [14] and in hereditary diseases like cystic fibrosis [20]. This test has prognostic relevance because it predicts clinical outcomes in several categories of patients including elderly patients undergoing coronary artery bypass grafting [23] and patients with chronic heart failure treated with cardiac resynchronization [24]. Whether this test of motor fitness predicts mortality in dialysis patients has never been investigated. In this study, we found coherent correlations between physical performance (6MWT) and some factors which have an obvious influence on health status, such as age, gender, cardiovascular comorbidities, NYHA class, diabetes, diastolic blood pressure and other parameters [25-29]. However, only age, gender and cardiovascular comorbidities maintained an independent association with the 6MWT suggesting that these factors are major determinants of motor fitness in dialysis patients. According to our working hypothesis that physical performance measured by the 6MWT holds prognostic value in dialysis patients, we found that this test is a strong predictor of mortality, cardiovascular events and hospitalizations in this population. More specifically, in adjusted analyses, we observed a reduction of $6 \%$ in the combined outcome for each increase of 20 walked meters, and a reduction of $12 \%$ and $4 \%$ for all cause death and hospitalization. Thus our data extend to the dialysis population observations made in other conditions $[23,24]$ and underscore the relevance of objective measures of motor fitness in assessing the overall risk profile of dialysis patients.

Future studies, including phase- 2 of EXCITE, will assess whether interventions aimed at improving physical fitness may translate into better clinical outcomes, including better physical performance, longer survival and reduced rate of cardiovascular events and hospitalizations in dialysis patients.

\section{Disclosure Statement}

The author of this article confirm that there are no conflicts to interest.

\section{References}

1 Paintera P, Roshanravan B: The association of physical activity and physical function with clinical outcomes in adults with chronic kidney disease. Curr Opin Nephrol Hypertens 2013;22:615-623.

$\checkmark 2$ Zoccali C: Traditional and emerging cardiovascular and renal risk factors: an epidemiologic perspective. Kidney Int 2006;70:26-33.

3 Nocon M, Hiemann T, Müller-Riemenschneider F, Thalau F, Roll S, Willich SN: Association of physical activity with all-cause and cardiovascular mortality: a systematic review and meta-analysis. Eur J Cardiovasc Prev Rehabil 2008;15:239-246.

4 Blomster JI Chow CK, Zoungas S, Woodward M, Patel A, Poulter NR, Marre M, Harrap S, Chalmers J, Hillis GS: The influence of physical activity on vascular complications and mortality in patients with type 2 diabetes mellitus. Diabetes Obes Metab 2013;15:1008-1012.

-5 Kutner NG, Zhang R, Huang Y, Herzog CA: Cardiac rehabilitation and survival of dialysis patients after coronary bypass. J Am Soc Nephrol 2006;17:1175-1180.

6 O'Hare AM, Tawney K, Bacchetti P, Johansen KJ: Decreased survival among sedentary patients undergoing dialysis: results from the Dialysis Morbidity and Mortality Study Wave 2. Am J Kidney Dis 2003;41:447454.

7 Stack AG, Molony DA, Rives T, Tyson J, Murthy BV: Association of physical activity with mortality in the US dialysis population. Am J Nephrol 2005;45:690-701.

Matsuzawa R, Matsunaga A, Wang G, Kutsuna T, Ishii A, Abe Y, Takagi Y, Yoshida A, Takahira N: Habitual physical activity measured by accelerometer and survival in maintenance hemodialysis patients. Clin J Am Soc Nephrol 2012;7:2010-2016. 


\section{Kidney \\ Blood Pressure Research}

Torino/Manfredini/Bolignano et al.: Physical Performance and Clinical Outcomes in Dialysis Patients: A Secondary Analysis of the Excite Trial

-9 Tentori F, Elder SJ, Thumma J, Pisoni RL, Bommer J, Fissell RB, Fukuhara S, Jadoul M, Keen ML, Saran R, Ramirez SP, Robinson BM: Physical exercise among participants in the Dialysis Outcomes and Practice Patterns Study (DOPPS): correlates and associated outcomes. Nephrol Dial Transplant 2010;25:3050-3062.

$\checkmark 10$ de Moraes Kohl L, Signori LU, Ribeiro RA, Vargas Silva AM, Moreira PR, Dipp T, Sbruzzi G, Lukrafka JL, Della Méa Plentz R: Prognostic value of the six-minute walk test in end-stage renal disease life expectancy: a prospective cohort study. Clinics (Sao Paulo) 2012;67:581-586.

11 Balke B: A simple field test for the assessment of physical fitness. Rep Civ Aeromed Res Inst US 1963;53:18.

12 Pinna GD, Opasich C, Mazza A, Tangenti A, Maestri R, Sanarico M: Reproducibility of the six-minute walking test in chronic heart failure patients. Stat Med 2000;19:3087-3094.

13 Opasich C, Pinna GD, Mazza A, Febo O, Riccardi PG, Capomolla S, Cobelli F, Tavazzi L: Reproducibility of the six-minute walking test in patients with chronic congestive heart failure: practical implications. Am J Cardiol 1998;81:1497-1500.

14 Hajiro T, Nishimura K, Tsukino M, Ikeda A, Koyama H, Izumi T: Analysis of clinical methods used to evaluate dyspnea in patients with chronic obstructive pulmonary disease. Am J Respir Crit Care Med 1998;158:1185-1189.

-15 2009 Focused Update Incorporated Into the ACC/AHA 2005 Guidelines for the Diagnosis and Management of Heart Failure in Adults: A Report of the American College of Cardiology Foundation/American Heart Association Task Force on Practice Guidelines: Developed in Collaboration With the International Society for Heart and Lung Transplantation. Circulation 2009;119:e391-e479.

16 Johansen KL, Chertow GM, Kutner NG, Dalrymple LS, Grimes BA, Kaysen GA: Low level of self-reported physical activity inambulatory patients newto dialysis. Kidney Int 2010;78:1164-1170.

17 Johansen KL, Chertow GM, Ng AV, Mulligan K, Carey S, Schoenfeld PY, Kent-Braun JA: Physical activity levels in patients on hemodialysis and healthy sedentary controls. Kidney Int 2000;57:2564-2570.

18 Zamojska S, Szklarek M, Niewodniczy M, Nowicki M: Correlates of habitual physical activity in chronic haemodialysis patients. Nephrol Dial Transplant 2006;21:11323-11327.

19 Gulmans VA, van Veldhoven NH, de Meer K, Helders PJ: The six-minute walking test in children with cystic fibrosis: reliability and validity. Pediatr Pulmonol 1996;22:85-89.

20 Chetta A, Pisi G, Zanini A, Foresi A, Grzincich GL, Aiello M, Battistini A, Olivieri D: Six-minute walking test in cystic fibrosis adults with mild to moderate lung disease: comparison to healthy subjects. Respir Med 2001;95:986-991.

21 Gualeni A, D'Aloia A, Gentilini A, Pagani M, Giordano A, Faggiano P: Effects of maximally tolerated oral therapy on the six-minute walking test in patients with chronic congestive heart failure secondary to either ischemic or idiopathic dilated cardiomyopathy. Am J Cardiol 1998;81:1370-1372.

22 Provenier F, Jordaens L: Evaluation of six minute walking test in patients with single chamber rate responsive pacemakers. Br Heart J 1994;72:192-196.

-23 Cacciatore F, Abete P, Mazzella F, Furgi G, Nicolino A, Longobardi G, Testa G, Langellotto A, Infante T, Napoli C, Ferrara N, Rengo F: Six-minute walking test but not ejection fraction predicts mortality in elderly patients undergoing cardiac rehabilitation following coronary artery bypass grafting. Eur J Prev Cardiol 2012;19:1401-1409.

24 Castel MA, Méndez F, Tamborero D, Mont L, Magnani S, Tolosana JM, Berruezo A, Godoy M, Sitges M, Vidal B, Roig E, Brugada J: Six-minute walking test predicts long-term cardiac death in patients who received cardiac resynchronization therapy. Europace 2009;11:338-342.

25 Cesari M, Costanzo L, Giua R, Vellas B, Incalzi RA: Physical Function and Exercise in Older Patients with Cardiovascular and Respiratory Conditions. Curr Pharm Des 2014;20:3198-3214.

26 Sinclair AJ , Conroy SP, Bayer AJ: Impact of diabetes on physical function in older people. Diabetes Care 2008;31:233-235.

27 Yano Y Inokuchi T, Hoshide S, Kanemaru Y, Shimada K, Kario K: Association of poor physical function and cognitive dysfunction with high nocturnal blood pressure level in treated elderly hypertensive patients. Am J Hypertens 2011;24:285-291.

-28 Aung KC, Feng L, Yap KB, Sitoh YY, Leong IY, Ng TP: Serum albumin and hemoglobin are associated with physical function in community-living older persons in Singapore. J Nutr Health Aging 2011;15:877-882.

-29 Ulvik B, Wentzel-Larsen T, Hanestad BR, Omenaas E, Nygård OK: Relationship between provider-based measures of physical function and self-reported health-related quality of life in patients admitted for elective coronary angiography. Heart Lung 2006;35:90-100. 